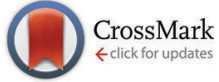

Cite this: J. Mater. Chem. C, 2015, 3, 7499

\section{Hydroxyl radical-assisted decomposition and oxidation in solution-processed indium oxide thin-film transistors}

\author{
Mardhiah M. Sabri, Joohye Jung, Doo Hyun Yoon, Seokhyun Yoon, Young Jun Tak \\ and Hyun Jae Kim*
}

Solution-processed indium oxide TFTs were fabricated by hydroxyl radical-assisted (HRA) decomposition and oxidation. The results show that decomposition and oxidation of carbon is more substantial than metal hydroxides, leading to the elimination of organic residues, correlated to a low interface trap density (S.S. $=0.45 \mathrm{~V} \mathrm{dec}{ }^{-1}, N_{T}=1.11 \times 10^{12} \mathrm{~cm}^{-2}$ ) in the device. The resultant HRA indium oxide TFTs exhibit improved electrical characteristics such as the mobility, the on/off current ratio, and the subthreshold swing as well as bias stabilities under PBS and NBS conditions.
Received 21st May 2015,

Accepted 17th June 2015

DOI: $10.1039 / c 5 t c 01457 c$

www.rsc.org/MaterialsC mobility as that of undoped $\operatorname{In}_{2} \mathrm{O}_{3}$. It is therefore advantageous to produce $\mathrm{In}_{2} \mathrm{O}_{3}$ TFTs without using dopants to maintain low annealing temperatures. However, obtaining $\mathrm{In}_{2} \mathrm{O}_{3}$ TFTs with high field effect mobility combined with excellent bias stability at low annealing temperatures as well as without metal dopants remains a challenge.

Herein, we demonstrate the fabrication of $\operatorname{In}_{2} \mathrm{O}_{3}$ TFTs using hydroxyl radical-assisted (HRA) decomposition and oxidation. The generation of hydroxyl radicals was accomplished by incorporating and activating hydrogen peroxide in the $\operatorname{In}_{2} \mathrm{O}_{3}$ precursor solution. Different from our previous study which focused on general hydrogen peroxide doping, ${ }^{16}$ this study focuses on hydroxyl radical-assisted decomposition and oxidation. Moreover, we employ a significantly lower annealing temperature suitable for flexible substrates. By using the HRA method, we successfully produce $\operatorname{In}_{2} \mathrm{O}_{3}$ films with low trap sites and TFT characteristics exhibiting excellent field effect mobility and stabilities at a low temperature of $240{ }^{\circ} \mathrm{C}$. In this report, we discuss the HRA decomposition and oxidation of $\operatorname{In}_{2} \mathrm{O}_{3}$ TFTs and characterize their electrical performance and stabilities.

\section{Experimental}

A $0.3 \mathrm{M}$ indium oxide solution was made by dissolving indium nitrate hydrate $\left(\operatorname{In}\left[\mathrm{NO}_{3}\right]_{3} \cdot x \mathrm{H}_{2} \mathrm{O}\right)$ in $10 \mathrm{~mL}$ of 2-methoxyethanol (2ME). Then, nitric acid $\left(\mathrm{HNO}_{3}\right)$ was added. The precursor solution was stirred at $320 \mathrm{rpm}$ for 4 hours and maintained at a temperature of $60{ }^{\circ} \mathrm{C}$ to create a homogeneous and transparent solution. Following that, the prepared solution was filtered through a $0.2 \mu \mathrm{m}$ micro filter and spin-coated at $3000 \mathrm{rpm}$ onto a substrate to form the active layer of thin-film 
transistors (TFTs). A total of four samples were prepared: (1) pristine $\mathrm{In}_{2} \mathrm{O}_{3}$, (2) $\mathrm{In}_{2} \mathrm{O}_{3}-\mathrm{H}_{2} \mathrm{O}_{2}$, (3) $\mathrm{In}_{2} \mathrm{O}_{3}-\mathrm{HRA}$, and (4) $\mathrm{In}_{2} \mathrm{O}_{3}-\mathrm{UV}$. For pristine $\mathrm{In}_{2} \mathrm{O}_{3}$ TFTs, the solution is coated as it is. For $\operatorname{In}_{2} \mathrm{O}_{3}-$ $\mathrm{H}_{2} \mathrm{O}_{2}$ TFTs, $30 \%$ volume hydrogen peroxide $\left(\mathrm{H}_{2} \mathrm{O}_{2}\right)$ was dispersed in pristine $\mathrm{In}_{2} \mathrm{O}_{3}$ solution. For $\operatorname{In}_{2} \mathrm{O}_{3}$-HRA TFTs, $\operatorname{In}_{2} \mathrm{O}_{3}-\mathrm{H}_{2} \mathrm{O}_{2}$ films were irradiated for 30 minutes with ultraviolet (UV) lamps with wavelengths of $185 \mathrm{~nm}$ and $254 \mathrm{~nm}$ at an intensity of $60 \mathrm{~mW} \mathrm{~cm}{ }^{-2}$ to generate hydroxyl radicals $\left(\mathrm{OH}^{\bullet}\right)$. To exclude the effect of UV light, pristine $\operatorname{In}_{2} \mathrm{O}_{3}$ was also irradiated following the same UV illumination procedure, herein referred to as $\mathrm{In}_{2} \mathrm{O}_{3}-\mathrm{UV}$. All fabricated TFTs employed a bottom-gate, top-contact configuration. $\mathrm{SiO}_{2} / \mathrm{p}^{+}$-Si substrates $(120 \mathrm{~nm})$ were used as gate dielectrics/gate. The coated active layer was annealed at $240{ }^{\circ} \mathrm{C}$ for 4 hours on a hot plate in ambient air. The source and drain electrodes ( $\mathrm{Al}, 100 \mathrm{~nm}$ ) were then deposited using a thermal evaporator with a shadow mask. The channel of the fabricated TFT devices was $1000 \mu \mathrm{m}$ wide and $150 \mu \mathrm{m}$ long.

Current-voltage $(I-V)$ characteristics of TFTs were measured at room temperature in a dark room using an HP4156C semiconductor parameter analyzer. Bias stability (positive bias stability, PBS; and negative bias stability, NBS) was recorded under the constant positive $(+20 \mathrm{~V})$ and negative $(-20)$ gate bias for $1000 \mathrm{~s}$ at room temperature. $V_{\mathrm{DS}}$ was set to $10.1 \mathrm{~V}$ and $V_{\mathrm{G}}$ was swept from $-30 \mathrm{~V}$ to $30 \mathrm{~V}$ to measure the stability. Chemical compositions of the oxide films were determined by Attenuated Total Reflection Fourier Transform Infrared (ATRFTIR, Bruker Vertex 70) spectroscopy, X-ray Photoelectron Spectroscopy (XPS, Thermo VG Scientific), and Electron Spin Resonance (ESR, Bruker BioSpin) spectroscopy. The FTIR data were measured in reflection mode at a resolution of $4 \mathrm{~cm}^{-1}$. The XPS data were recorded using a monochromatic $\mathrm{Al} \mathrm{K}$ source $(1486.6 \mathrm{eV})$ in an ultra-high vacuum system at a base pressure of $\sim 10^{-10}$ Torr. The $\mathrm{C} 1 \mathrm{~s}$ peak at $284.8 \mathrm{eV}$ was used for calibration. For ESR spectroscopy, spin-trapping was used due to the low concentration and the transient nature of the radicals.
5,5-Dimethyl-1-pyrroline $N$-oxide (DMPO) was chosen as a spin trap agent because of its well-documented trapping ability and selectivity for radicals. ${ }^{17-19}$

\section{Results and discussion}

The schematic illustration of the HRA decomposition and oxidation method is shown in Fig. 1a. $\mathrm{OH}^{\bullet}$ can be generated through UV irradiation because $\mathrm{H}_{2} \mathrm{O}_{2}$ absorbs wavelengths $\leq 350 \mathrm{~nm}$ subsequently causing photolytic cleavage to yield $\mathrm{OH}^{\bullet} .^{19-21}$ The irradiation generates two $\mathrm{OH}^{\bullet}$ per molecule of $\mathrm{H}_{2} \mathrm{O}_{2}$ as shown in eqn (1). In this photocatalytic reaction, $\mathrm{OH}^{\bullet}$ was produced as main species through photocatalysis.

$$
\mathrm{H}_{2} \mathrm{O}_{2} \stackrel{h v}{\longrightarrow} 2 \mathrm{OH}^{\bullet}
$$

Fig. $1 \mathrm{~b}$ displays the transfer characteristics of pristine $\operatorname{In}_{2} \mathrm{O}_{3}$, $\mathrm{In}_{2} \mathrm{O}_{3}-\mathrm{UV}, \mathrm{In}_{2} \mathrm{O}_{3}-\mathrm{H}_{2} \mathrm{O}_{2}$, and $\mathrm{In}_{2} \mathrm{O}_{3}-\mathrm{HRA}$ TFTs, and Table 1 summarizes their representative electrical parameters. The electrical parameters were extracted from transfer curves in the saturation regime using the transconductance $\left(g_{\mathrm{m}}\right)$ method:

$$
I_{\mathrm{DS}}=\left(\frac{C_{i} \mu_{\mathrm{FE}} W}{2 L}\right)\left(V_{\mathrm{GS}}-V_{\mathrm{TH}}\right)^{2} \text { for } V_{\mathrm{DS}}>V_{\mathrm{GS}}-V_{\mathrm{TH}}
$$

where $W$ is the channel width, $L$ is the channel length, and $C_{i}$ is the capacitance per unit area of the dielectric layer. HRA decomposition and oxidation results in the most decrease of the trap density and distinctly higher mobility with a better on/ off current ratio. As the trap density $\left(N_{\mathrm{T}}\right)$ was calculated from the subthreshold swing (S.S.), the decrease in the trap density also correlates to the improvement in the S.S. performance. In contrast, incorporation of energetic (4.88-6.70 eV) UV illumination without $\mathrm{OH}^{\bullet}$ may not decrease trap sites as shown for the $\mathrm{In}_{2} \mathrm{O}_{3}$-UV device. It is therefore commonly accepted that excess a

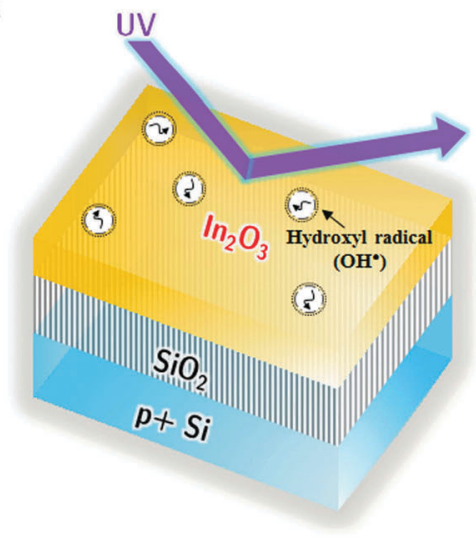

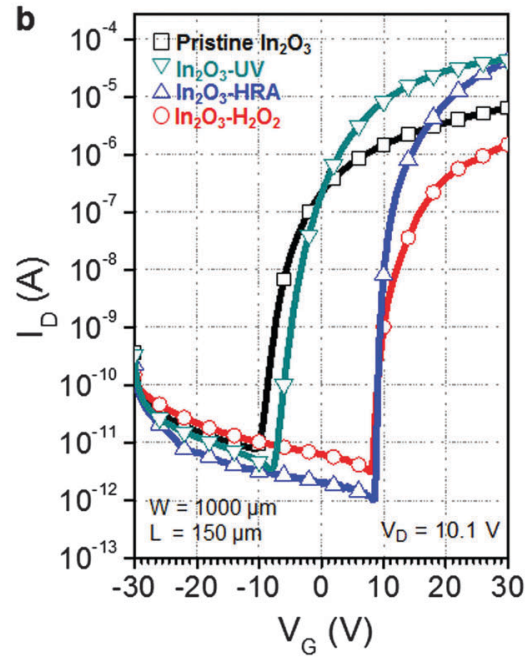

C Trap density $\left(\mathrm{N}_{\mathrm{T}}\right)$

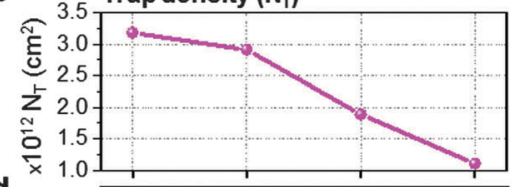

d

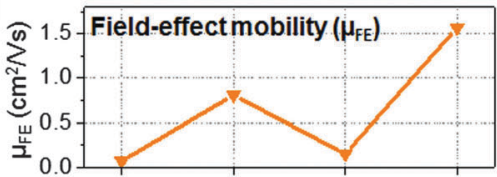

e

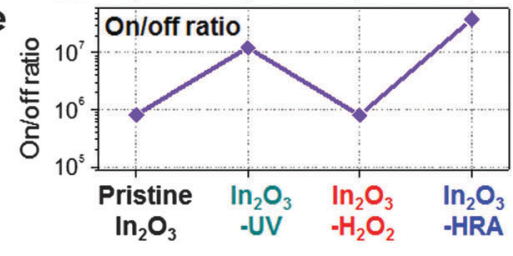

Fig. 1 (a) Schematic of a hydroxyl radical-assisted (HRA) method for solution-processed $\ln _{2} \mathrm{O}_{3}$ thin-films. (b) Transfer characteristics of bottom-gate, top-contact $\ln _{2} \mathrm{O}_{3}$ TFTs with the channel width $W=1000 \mu \mathrm{m}$ and the channel length $L=150 \mu \mathrm{m}$. (c) Trap density, (d) field-effect mobility, and (e) the on/off ratio of the $\ln _{2} \mathrm{O}_{3}$ TFTs. 
Table 1 Summary of electrical parameters of solution-processed $\ln _{2} \mathrm{O}_{3}$ TFTs

\begin{tabular}{lllll}
\hline Devices & $\begin{array}{l}\text { Mobility } \\
\left(\mathrm{cm}^{2} \mathrm{~V}^{-1} \mathrm{~s}^{-1}\right)\end{array}$ & $\begin{array}{l}\text { S.S. } \\
(\mathrm{V} \mathrm{dec}\end{array}$ & $N_{\mathrm{T}}\left(\mathrm{cm}^{-2}\right)$ & On/off ratio \\
\hline Pristine $\mathrm{In}_{2} \mathrm{O}_{3}$ & 0.07 & 1.17 & $3.18 \times 10^{12}$ & $8.13 \times 10^{5}$ \\
$\mathrm{In}_{2} \mathrm{O}_{3}-\mathrm{UV}$ & 0.81 & 1.08 & $2.91 \times 10^{12}$ & $1.23 \times 10^{7}$ \\
$\mathrm{In}_{2} \mathrm{O}_{3}-\mathrm{H}_{2} \mathrm{O}_{2}$ & 0.15 & 0.72 & $1.89 \times 10^{12}$ & $8.02 \times 10^{5}$ \\
$\mathrm{In}_{2} \mathrm{O}_{3}-\mathrm{HRA}$ & 1.57 & 0.45 & $1.11 \times 10^{12}$ & $3.88 \times 10^{7}$
\end{tabular}

trap sites may occur due to the high excitation energy and ozone formation from UV illumination. The result implies that the HRA method both effectively reduces defects related to trap sites and sub-gap states and enhances the electrical characteristics such as the mobility, the on/off current ratio, and the S.S.

To verify the trap density reduction behavior, bias stabilities of pristine $\operatorname{In}_{2} \mathrm{O}_{3}, \operatorname{In}_{2} \mathrm{O}_{3}-\mathrm{H}_{2} \mathrm{O}_{2}$, and $\operatorname{In}_{2} \mathrm{O}_{3}-\mathrm{HRA}$ TFTs were investigated under PBS and NBS conditions (Fig. 2). The $\mathrm{In}_{2} \mathrm{O}_{3}-\mathrm{HRA}$ TFT showed a shift of $0.46 \mathrm{~V}$ upon the PBS and $0.65 \mathrm{~V}$ upon the NBS after $1000 \mathrm{~s}$. The instability of electrical properties under bias stress can be explained by two general mechanisms: (1) the defect creation model and (2) the charge trapping model. In the defect creation model, $V_{\mathrm{ON}}$ shifts with deterioration of S.S. as a result of gate bias stress that induces formation of trap sites. In the charge trapping model, on the other hand, $V_{\mathrm{ON}}$ shifts without deterioration of S.S. It is widely believed that the $V_{\mathrm{ON}}$ shift $\left(\Delta V_{\mathrm{ON}}\right)$ is contributed by charges trapped at the dielectric/channel interface and inside the bulk of the channel, resulting in $\Delta V_{\mathrm{ON}}$ without a significant change in S.S. The charge trapping model is related to $\Delta V_{\mathrm{ON}}\left(\Delta V_{\mathrm{ON}}=\right.$ $\left.V_{\text {ON,Final }}-V_{\text {ON,Initial }}\right)$ and stress time using the stretchedexponential equation: ${ }^{22,23}$

$$
\Delta V_{\mathrm{ON}}=\Delta V_{\mathrm{ONO}}\left[1-\exp \left\{-(t / \tau)^{\beta}\right\}\right]
$$

where $V_{0}$ is the $V_{\mathrm{ON}}$ at the start of the experiment, $\tau$ is the characteristic trapping time of electron carriers, $t$ is the stress duration time, and $\beta$ is $T / T_{0}$. As shown in Fig. 2, transfer curves of the $\mathrm{In}_{2} \mathrm{O}_{3}$-HRA TFT show no degradation of S.S. and only a small parallel shift. This result indicates that the $\operatorname{In}_{2} \mathrm{O}_{3}-\mathrm{HRA}$ TFT shows prominent improvements under both PBS and NBS conditions compared to the pristine $\operatorname{In}_{2} \mathrm{O}_{3}$ device owing to reduced trap sites.

In general, the trap sites in solution-processed oxide TFTs are intimately related to defects that inherently exist in the metal oxide channel layer. These defects include impurities and oxygen deficiencies. The presence of carbon impurities is inevitable because of the organic nature of the solvent. It is important to eliminate organic molecules to the highest possible degree because they can trap electrons, and are therefore detrimental
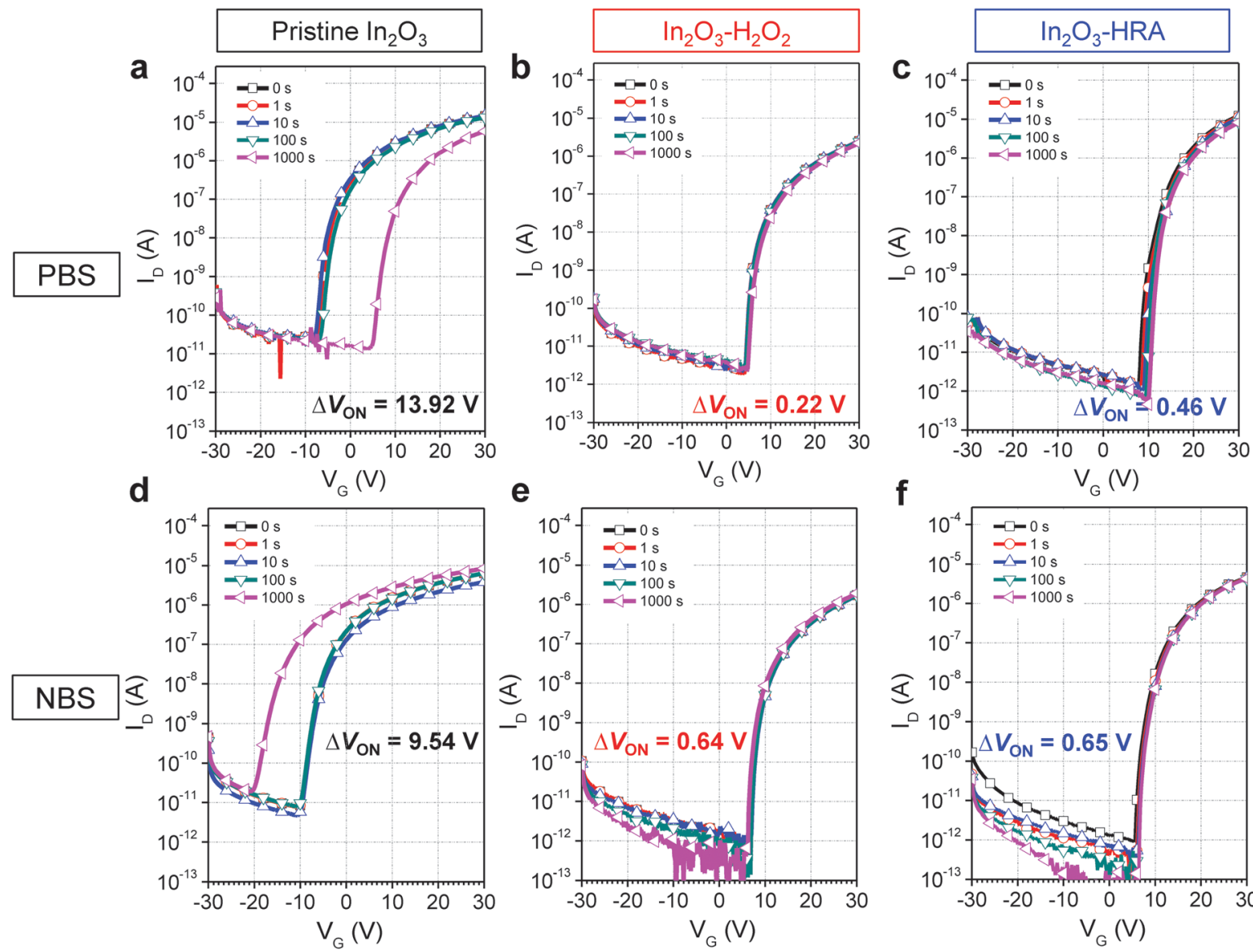

e

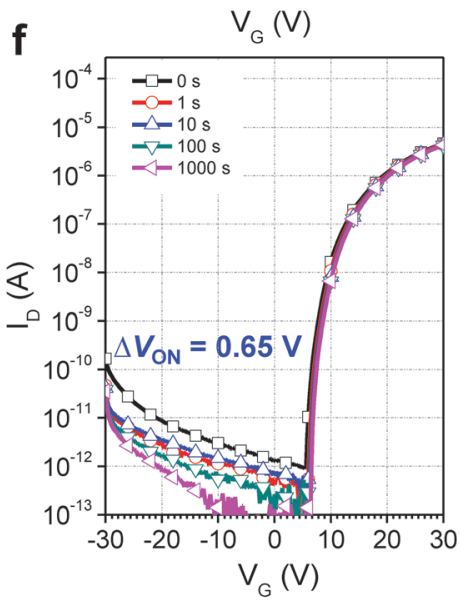

Fig. 2 Evaluation with positive bias stress $(a-c)$ and negative bias stress (d-f) for pristine $\ln _{2} \mathrm{O}_{3}$, (a) and (d); $\ln _{2} \mathrm{O}_{3}-\mathrm{H}_{2} \mathrm{O}_{2}$, (b) and (e); and $\ln 2 \mathrm{O}_{3}-\mathrm{HRA}$, (c) and (f); with a gate voltage of $20 \mathrm{~V}$ and $-20 \mathrm{~V}$ respectively for $1000 \mathrm{~s}$. 

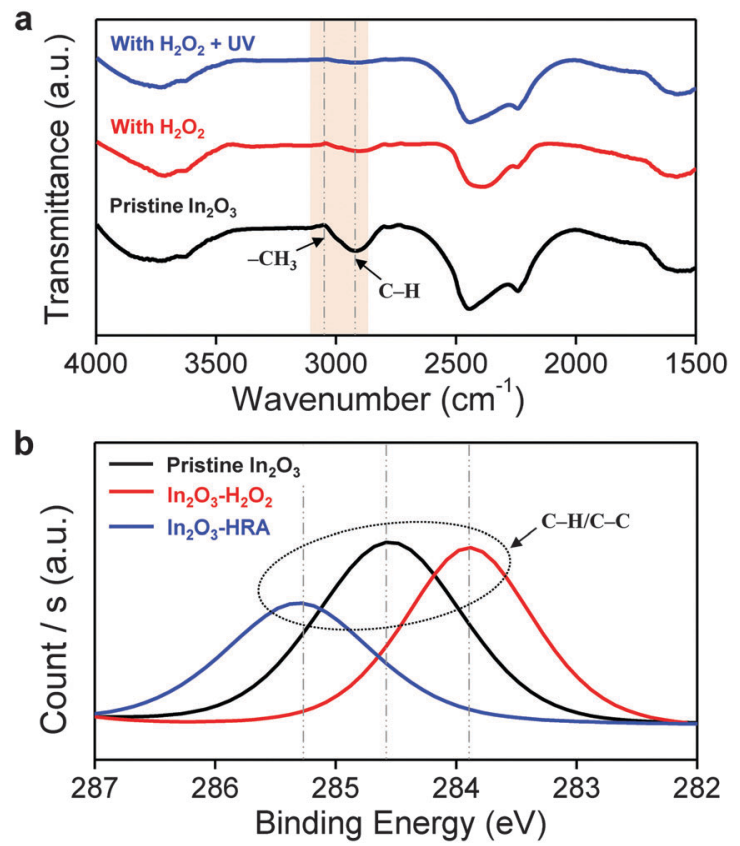

Fig. 3 Profile of (a) FTIR spectra and (b) XPS C 1 s spectra of pristine $\ln _{2} \mathrm{O}_{3}$, $\mathrm{In}_{2} \mathrm{O}_{3}-\mathrm{H}_{2} \mathrm{O}_{2}$, and $\mathrm{In}_{2} \mathrm{O}_{3}-\mathrm{HRA}$ films.

to device operation. ${ }^{24}$ In this regard, the reduction of carbon impurities in the $\mathrm{In}_{2} \mathrm{O}_{3}$-HRA film was confirmed by FTIR (Fig. 3a) and XPS (Fig. 3b). In Fig. 3a, the $\mathrm{C}-\mathrm{H}$ peak in the range $2950-2900 \mathrm{~cm}^{-1}$ and the $\mathrm{CH}_{3}$ peak in the range 3100$3000 \mathrm{~cm}^{-1}$ were absent. ${ }^{25,26}$ The absence of these bands implies a pronounced elimination of carbon impurities in the thin film. Similarly, in the C 1s spectra (Fig. 3b), the characteristic peak corresponding to the $\mathrm{C}-\mathrm{H} / \mathrm{C}-\mathrm{C}$ peak $(\sim 285 \pm 0.6 \mathrm{eV})$ shows the lowest concentration for the $\operatorname{In}_{2} \mathrm{O}_{3}$-HRA film. ${ }^{27}$ Furthermore, the total atomic ratio for carbon summarized in Fig. 5a indicates that impurities were reduced from $21.86 \%$ to $16.64 \%$ for the HRA method. These results verify the reduction of carbon impurities in the final HRA thin film.

The XPS $\mathrm{O}$ 1s peaks of pristine $\operatorname{In}_{2} \mathrm{O}_{3}, \mathrm{In}_{2} \mathrm{O}_{3}-\mathrm{H}_{2} \mathrm{O}_{2}$, and $\mathrm{In}_{2} \mathrm{O}_{3}$-HRA TFTs are shown in Fig. 4. The $\mathrm{O} 1 s$ peaks are deconvoluted to $530.7 \mathrm{eV}$ (green lines), $531.8 \mathrm{eV}$ (blue lines), and $532.9 \mathrm{eV}$ (orange lines) denoting oxygen bonded to metals $(\mathrm{M}-\mathrm{O})$, oxygen deficiencies $\left(V_{\mathrm{o}}\right)$, and surface hydroxyl species (M-OH) respectively. ${ }^{28,29}$ The HRA $\operatorname{In}_{2} \mathrm{O}_{3}$ films exhibit a lower degree of hydroxyl species, as expected, despite an increase in oxygen deficiencies. As hydroxide lattices are less efficient in transporting carriers due to broken short intercation distances, it is desirable to reduce $\mathrm{M}-\mathrm{OH}$ to the lowest possible degree. For $\operatorname{In}_{2} \mathrm{O}_{3}$, formation energy of $V_{\mathrm{o}}$ is reportedly lower than that of $\mathrm{M}-\mathrm{O} .{ }^{13}$ In the HRA method, molecular oxygen was also produced (eqn (4)) in addition to $\mathrm{OH}^{\bullet}$ owing to ozone formation. Moreover, decomposition of $\mathrm{H}_{2} \mathrm{O}_{2}$ through homolysis (eqn (5)) also yielded molecular oxygen.

$$
\begin{gathered}
\mathrm{H}_{2} \mathrm{O}_{2} \stackrel{2 \mathrm{O}_{3}}{\longrightarrow} 2 \mathrm{OH}^{\bullet}+3 \mathrm{O}_{2} \\
2 \mathrm{H}_{2} \mathrm{O}_{2} \rightarrow 2 \mathrm{H}_{2} \mathrm{O}+\mathrm{O}_{2}
\end{gathered}
$$

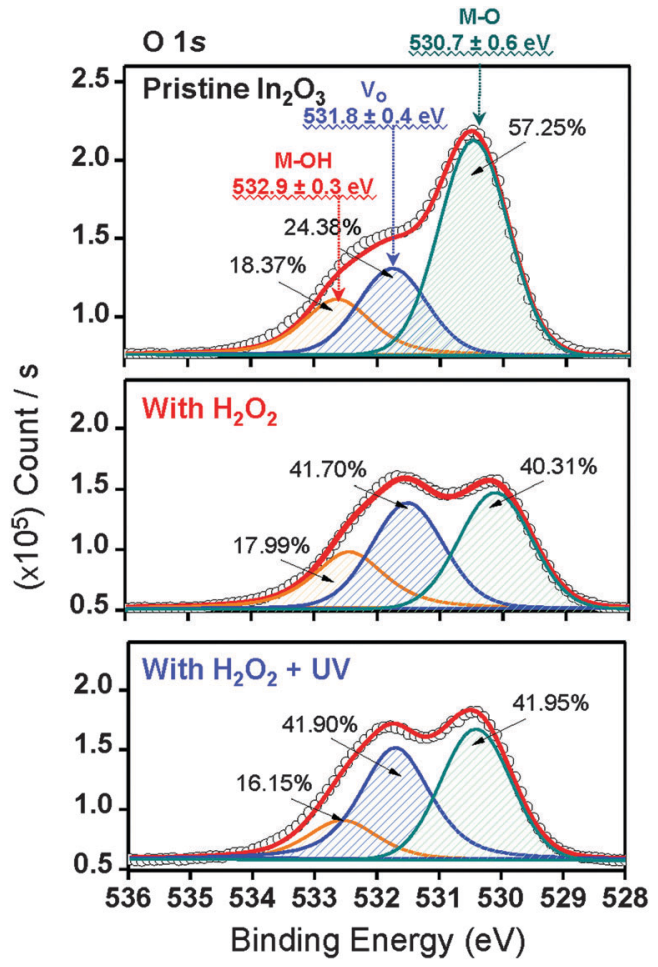

Fig. 4 Representative XPS O 1 s peaks for pristine $\ln _{2} \mathrm{O}_{3}, \ln _{2} \mathrm{O}_{3}-\mathrm{H}_{2} \mathrm{O}_{2}$, and $\mathrm{In}_{2} \mathrm{O}_{3}$-HRA TFTs. The peaks were fitted representing metal hydroxides $(\mathrm{M}-\mathrm{OH} ; 532.9 \pm 0.3 \mathrm{eV})$, oxygen deficiencies $\left(V_{0} ; 531.8 \pm 0.4 \mathrm{eV}\right)$, and metal oxides (M-O; $530.7 \pm 0.6 \mathrm{eV}$ ).

Therefore incorporation of oxygen through the HRA method elevated the oxygen content in the lattice as expected. This relationship between oxygen supply and oxygen deficiency formation energy implies that the increase of $V_{\mathrm{o}}$ observed is due to the additional oxygen supply and not due to defect creation. The quantitative analyses by XPS verify this incorporation of oxygen, showing an increase in the total atomic ratios of oxygen in Fig. 5b.

As a simple method that enables both improved mobility and bias stability of $\operatorname{In}_{2} \mathrm{O}_{3}$ TFTs, we introduced $\mathrm{OH}^{\bullet}$ during the film formation process by adding and activating $\mathrm{H}_{2} \mathrm{O}_{2}$. The formation
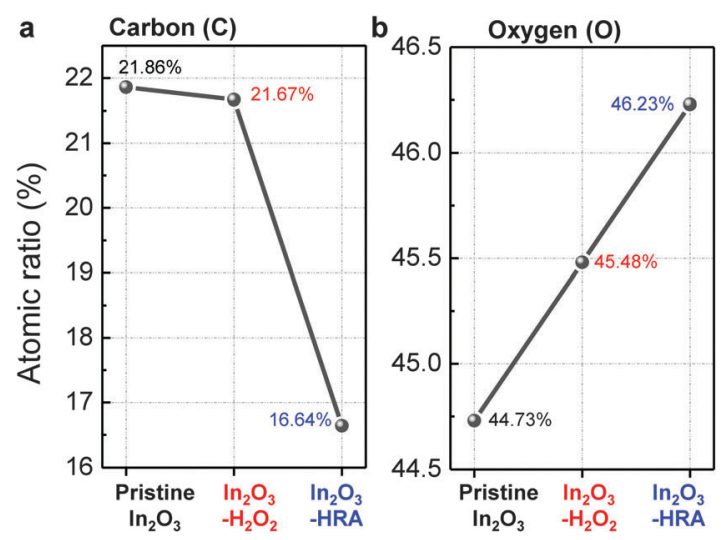

Fig. 5 Summarized atomic ratio of (a) carbon and (b) oxygen. 


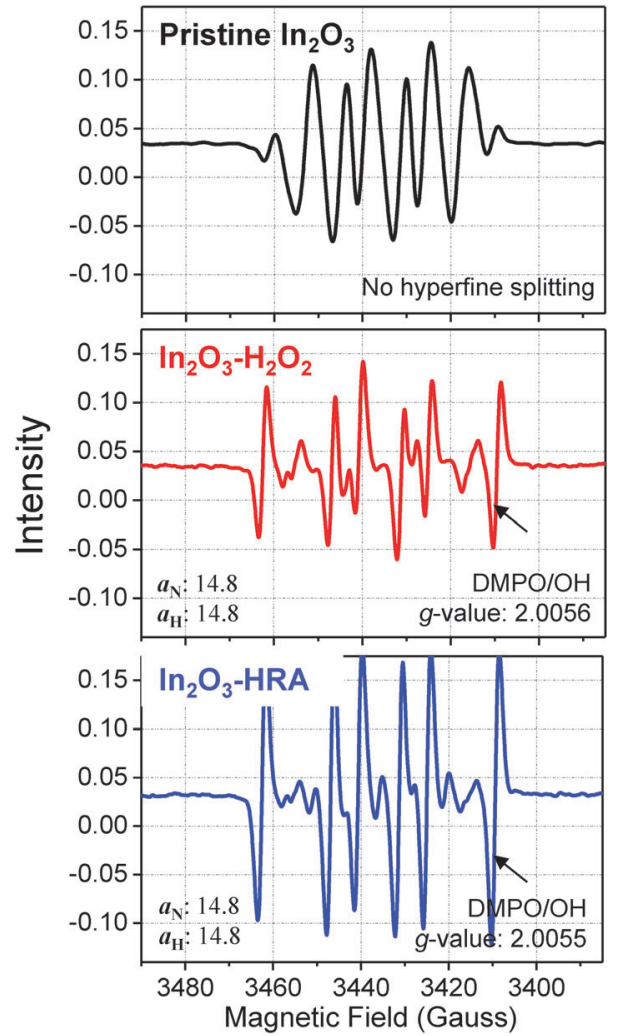

Fig. 6 ESR spectra of hydroxyl radicals as detected by the DMPO/OH adduct.

of $\mathrm{OH}^{\bullet}$ was confirmed by ESR spectroscopy (Fig. 6) using a spin trap agent, 5,5-dimethyl-1-pyrroline $N$-oxide (DMPO). The use of a spin trap agent was necessary due to the transient and shortlived nature of the radicals. ${ }^{30}$ In Fig. 6, the intensity of DMPO/ $\mathrm{OH}$ spectra of the $\mathrm{In}_{2} \mathrm{O}_{3}$-HRA film was superior to that of $\operatorname{In}_{2} \mathrm{O}_{3}-$ $\mathrm{H}_{2} \mathrm{O}_{2}$. The DMPO/OH spectra are characterized by $g$-factors of $2.0056\left(\mathrm{In}_{2} \mathrm{O}_{3}-\mathrm{H}_{2} \mathrm{O}_{2}\right)$ and $2.0055\left(\mathrm{In}_{2} \mathrm{O}_{3}-\mathrm{HRA}\right)$, splitting by one ${ }^{14} \mathrm{~N}$ nucleus $\left(a_{\mathrm{N}}=14.8 \mathrm{G}\right)$ and one ${ }^{1} \mathrm{H}$ nucleus $\left(a_{\mathrm{H}}=14.8 \mathrm{G}\right)$, respectively. ${ }^{31}$ This result verify that $\mathrm{UV}$ illumination is critical to generate a significant amount of $\mathrm{OH}^{\bullet}$, as expected in eqn (1).
The incorporation of $\mathrm{OH}^{\bullet}$ into $\operatorname{In}_{2} \mathrm{O}_{3}$ synthesis is advantageous for the following two reasons.

\section{(i) $\mathrm{OH}^{\bullet}$ as a decomposition agent}

The generation of $\mathrm{OH}^{\bullet}$ in a precursor solution is capable of breaking down organic substrates into smaller molecules. Fig. 7 shows the proposed reaction scheme of HRA decomposition and oxidation. Because organic molecules in the precursor solution primarily originate from the solvent, it is therefore important to focus on the chemical composition of 2-methoxyethanol. Such alkoxyethanols possess two functional groups: (1) alcoholic hydroxyl $(-\mathrm{OH})$ and (2) etheric oxy (-O-) groups. ${ }^{32}$ Ross and co-workers suggested that oxidation in 2-methoxyethanol occurs through electron transfer at the etheric oxy group rather than the hydroxyl group. ${ }^{33}$ Upon generation of $\mathrm{OH}^{\bullet}$ from $\mathrm{H}_{2} \mathrm{O}_{2}$, the unpaired electron from $\mathrm{OH}^{\bullet}$ is discharged at the etheric oxygen which is followed by fission of the $\mathrm{C}-\mathrm{C}$ and/or $\mathrm{C}-\mathrm{H}$ bonds between the oxygen atoms. Subsequently, the chain is further degraded leading to the cleavage of $-\mathrm{O}-\mathrm{CH}_{2}-\mathrm{CH}_{2}$. The reaction produces cation I and formaldehyde II. Then cation I and formaldehyde II are oxidized to yield ethyl formate III and aldehyde IV respectively. ${ }^{34}$ These smaller molecules can be effectively evaporated, resulting in reduced impurities. The specifics of electron transfer are challenging, but the products obtained indicate that the overall process, probably occurring in a series of steps, is one in which $\mathrm{OH}^{\bullet}$ oxidizes etheric oxygen and breaks down the methyl group into smaller formaldehyde. With more $\mathrm{OH}^{\bullet}$ available for transfer of electrons to the etheric oxy group, ${ }^{33}$ ultimately oxidizing a carbon atom, a significant decrease in carboxylic groups was observed in the end film.

\section{(ii) $\mathrm{OH}^{\bullet}$ as an oxidizing agent}

$\mathrm{OH}^{\bullet}$ can oxidize sub-gap states from a near conduction band minimum (CBM) state to shallow states, shown in Fig. 8. In amorphous oxides, the states can be located above the valence band maximum (VBM, near-VBM) and below the CBM (near-VBM). ${ }^{35}$ In the near-VBM state, the localized states are reportedly occupied by electron-acceptors which consist of oxygen sites and low valence cations $\left(\mathrm{In}^{3+}\right.$ from In $4 \mathrm{~d}$ and $\left.5 \mathrm{~s}\right){ }^{13}$ In the near-CBM state, on the

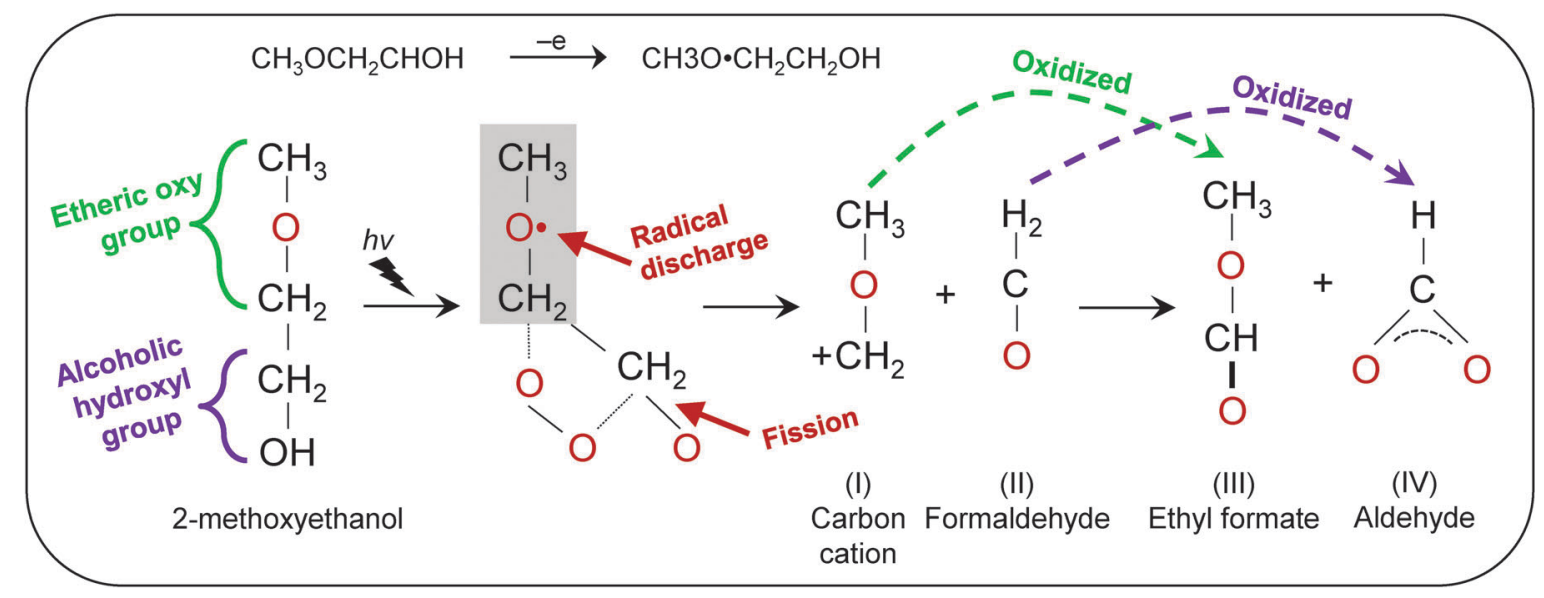

Fig. 7 Proposed reaction scheme of the hydroxyl radical-assisted decomposition of solution with 2-methoxyethanol solvent. 


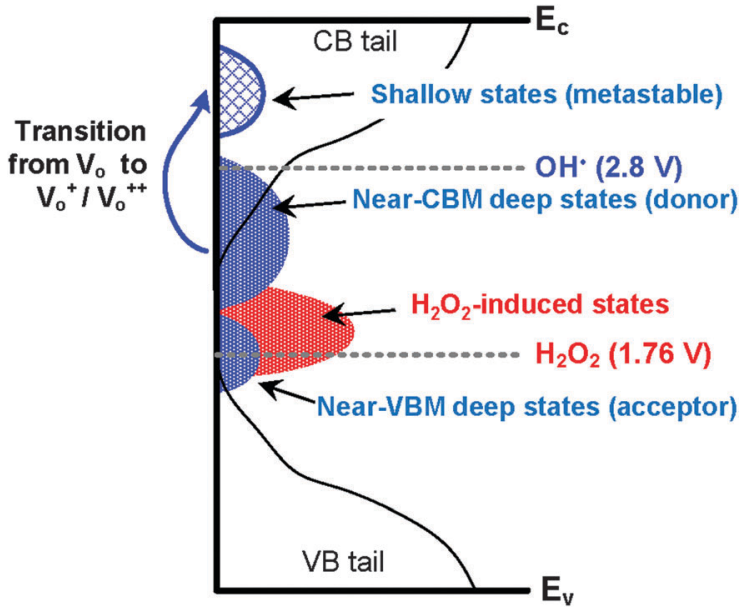

Fig. 8 Schematic illustrations of the hydroxyl-radical assisted oxidation inducing metastable states.

other hand, the band consists of electron-donors. The donor-type states are occupied at a neutral charge and can provide electrons by ionization. Fig. 8 shows the schematic illustrations of HRA oxidation that converts neutral near-CBM states to shallow states. It is commonly accepted that $V_{\mathrm{o}}$ in $\operatorname{In}_{2} \mathrm{O}_{3}$ are donors, owing to the high density of oxygen sites very close to and just below the CBM. ${ }^{35}$ In the neutral charge state, $V_{\mathrm{o}}$ in the near-CBM states exhibit inward relaxation by binding two electrons. For $\mathrm{In}_{2} \mathrm{O}_{3}-\mathrm{H}_{2} \mathrm{O}_{2}$, the incorporation of $\mathrm{H}_{2} \mathrm{O}_{2}$ is expected to induce states located near-VBM, which are electron acceptors. In contrast, for $\operatorname{In}_{2} \mathrm{O}_{3}-\mathrm{HRA}$, the incorporation of high density $\mathrm{OH}^{\bullet}$ is expected to chemically ionize the neutral $V_{\mathrm{o}}$ to give rise to the singly ionized state $\left(V_{\mathrm{o}}^{+}\right)$and the doubly ionized state $\left(V_{\mathrm{o}}{ }^{++}\right)$due to its strong oxidation potential. ${ }^{21}$ Both of the ionized states are metastable because they are located above the CBM, and are therefore capable of both trapping and donating electrons. ${ }^{36}$ For the $\mathrm{In}_{2} \mathrm{O}_{3}$-HRA TFT, our results indicate that electron donor behavior is more dominant for these metastable states.

\section{Conclusions}

In summary, we have demonstrated $\operatorname{In}_{2} \mathrm{O}_{3}$ TFTs exhibiting improved mobility and bias stabilities via a hydroxyl radical-assisted decomposition and oxidation approach. In the thin film formation, hydroxyl radicals reduce carbon impurities and induce the formation of metastable states. In addition, the low annealing temperature that was demonstrated indicates potential for manipulating oxidizing agents in pursuit of low-temperature and high-performance solutionbased flexible oxide electronics at low manufacturing cost.

\section{Acknowledgements}

This work was supported by (1) the Industrial Strategic Technology Development Program (10041808, Synthesis of Oxide Semiconductor and Insulator Ink Materials \& Process Development for Printed Backplane of Flexible Displays Processed below $150{ }^{\circ} \mathrm{C}$ ) funded by the Ministry of Knowledge Economy (MKE, Korea), and (2) the National Research Foundation of Korea (NRF) grant funded by the Korea government (MSIP) (No. 2011-0028819). We thank Dr M. Shahbuddin of the Kroto Research Institute, University of Sheffield, Sheffield, UK for insightful discussions on organic substrates and FTIR.

\section{References}

1 E. Fortunato, P. Barquinha and R. Martins, Adv. Mater., 2012, 24, 2945-2986.

2 K. Nomura, H. Ohta, A. Takagi, T. Kamiya, M. Hirano and H. Hosono, Nature, 2004, 432, 488-492.

3 P. Barquinha, L. Pereira, G. Goncalves, R. Martins and E. Fortunato, J. Electrochem. Soc., 2009, 156, H161-H168.

4 S. J. Heo, D. H. Yoon, T. S. Jung and H. J. Kim, J. Inf. Disp., 2013, 14, 79-87.

5 S. J. Kim, S. Yoon and H. J. Kim, Jpn. J. Appl. Phys., 2014, 53, 02 BA02.

6 H. Nakazawa, Y. Ito, E. Matsumoto, K. Adachi, N. Aoki and Y. Ochiai, J. Appl. Phys., 2006, 100, 093706.

7 H. S. Kim, P. D. Byrne, A. Facchetti and T. J. Marks, J. Am. Chem. Soc., 2008, 130, 12580-12581.

8 M.-G. Kim, M. G. Kanatzidis, A. Facchetti and T. J. Marks, Nat. Mater., 2011, 10, 382-388.

9 S.-Y. Han, G. S. Herman and C.-h. Chang, J. Am. Chem. Soc., 2011, 133, 5166-5169.

10 L. Petti, H. Faber, N. Münzenrieder, G. Cantarella, P. A. Patsalas, G. Tröster and T. D. Anthopoulos, Appl. Phys. Lett., 2015, 106, 092105.

11 H. Faber, Y.-H. Lin, S. R. Thomas, K. Zhao, N. Pliatsikas, M. A. McLachlan, A. Amassian, P. A. Patsalas and T. D. Anthopoulos, ACS Appl. Mater. Interfaces, 2015, 7, 782-790.

12 C.-H. Choi, S.-Y. Han, Y.-W. Su, Z. Fang, L.-Y. Lin, C.-C. Cheng and C.-h. Chang, J. Mater. Chem. C, 2015, 3, 854-860.

13 A. Murat and J. E. Medvedeva, Phys. Rev. B: Condens. Matter Mater. Phys., 2012, 86, 085123.

14 N. Mitoma, S. Aikawa, W. Ou-Yang, X. Gao, T. Kizu, M.-F. Lin, A. Fujiwara, T. Nabatame and K. Tsukagoshi, Appl. Phys. Lett., 2015, 106, 042106.

15 M.-F. Lin, X. Gao, N. Mitoma, T. Kizu, W. Ou-Yang, S. Aikawa, T. Nabatame and K. Tsukagoshi, AIP Adv., 2015, 5, 017116.

16 J. M. Kwon, J. Jung, Y. S. Rim, D. L. Kim and H. J. Kim, ACS Appl. Mater. Interfaces, 2014, 6, 3371-3377.

17 M. Danilczuk, F. D. Coms and S. Schlick, J. Phys. Chem. B, 2009, 113, 8031-8042.

18 A. Bosnjakovic and S. Schlick, J. Phys. Chem. B, 2004, 108, 4332-4337.

19 J. R. Harbour, V. Chow and J. R. Bolton, Can. J. Chem., 1974, 52, 3549-3553.

20 L. Ghassemzadeh, T. J. Peckham, T. Weissbach, X. Luo and S. Holdcroft, J. Am. Chem. Soc., 2013, 135, 15923-15932.

21 C. W. Jones, Applications of Hydrogen Peroxide and Derivatives, Royal Society of Chemistry, 1999.

22 M. E. Lopes, H. L. Gomes, M. C. R. Medeiros, P. Barquinha, L. Pereira, E. Fortunato, R. Martins and I. Ferreira, Appl. Phys. Lett., 2009, 95, 063502. 
23 T.-C. Chen, T.-C. Chang, T.-Y. Hsieh, W.-S. Lu, F.-Y. Jian, C.-T. Tsai, S.-Y. Huang and C.-S. Lin, Appl. Phys. Lett., 2011, 99, 022104.

24 N. Fukuda, Y. Watanabe, S. Uemura, Y. Yoshida, T. Nakamura and H. Ushijima, J. Mater. Chem. C, 2014, 2, 2448-2454.

25 D. W. Mayo, F. A. Miller, R. W. Hannah and R. Wesley, Course Notes on The Interpretation of Infrared and Raman Spectra, Wiley Online Library, 2004.

26 K. Nakanishi and P. H. Solomon, Infrared Absorption Spectroscopy, Holden-Day, 1977.

27 X. Deng, A. Verdaguer, T. Herranz, C. Weis, H. Bluhm and M. Salmeron, Langmuir, 2008, 24, 9474-9478.

28 C. Donley, D. Dunphy, D. Paine, C. Carter, K. Nebesny, P. Lee, D. Alloway and N. R. Armstrong, Langmuir, 2002, 18, 450-457.
29 Y. J. Tak, D. H. Yoon, S. Yoon, U. H. Choi, M. M. Sabri, B. D. Ahn and H. J. Kim, ACS Appl. Mater. Interfaces, 2014, 6, 6399-6405.

30 C. Lagercrantz, J. Phys. Chem., 1971, 75, 3466-3475.

31 K. Makino, T. Hagiwara and A. Murakami, Int. J. Radiat. Appl. Instrum., Part C, 1991, 37, 657-665.

32 B. Das and D. K. Hazra, J. Phys. Chem., 1995, 99, 269-273.

33 S. D. Ross, J. E. Barry, M. Finkelstein and E. J. Rudd, J. Am. Chem. Soc., 1973, 95, 2193-2198.

34 S. Yamagata, R. Baba and A. Fujishima, Bull. Chem. Soc. Jpn., 1989, 62, 1004-1010.

35 K. Nomura, T. Kamiya, E. Ikenaga, H. Yanagi, K. Kobayashi and H. Hosono, J. Appl. Phys., 2011, 109, 073726.

36 H.-K. Noh, K. Chang, B. Ryu and W.-J. Lee, Phys. Rev. B: Condens. Matter Mater. Phys., 2011, 84, 115205. 